\title{
Research on mechanism about response of social governance theory to ethnic minorities' sports culture demands and national identity
}

\author{
Yingqing $\mathrm{Hu}^{1}$, Yunong $\mathrm{Wu}^{2}$, Xinping Jiang ${ }^{3^{*}}$ \\ ${ }^{1}$ Guangxi College of Sports and Physical Education, Nanning, 530012, China \\ ${ }^{2}$ Baise University, Baise, 533001, China \\ ${ }^{3}$ Guangxi University for Nationalities, Nanning, 530006, China \\ ${ }^{*}$ Corresponding author
}

Keywords: Social governance theory; mechanism about response to cultural needs; National identity

\begin{abstract}
Ethnic minorities' demands for sports culture also grow with each passing day in China currently as Chinese society advances continuously and economic level improves constantly. As a result, existing mechanism about response to cultural needs has failed to satisfy increasingly growing demands of ethnic minorities for sports culture because of its internal shortages. Based on this, this thesis roughly discusses mechanism about response of social governance theory to ethnic minorities' sports culture demands and national identity.

This research is funded y 'Research on mechanism about response to ethnic minorities' sports culture policy and national identity' a planned project about philosophy and social science in Guangxi Province and approval number of the project is 13BTY004.

Since Reform and Opening-up was implemented, Chinese economy and social consciousness has had earthshaking changes and both social civilization level and economic richness degree have got unprecedented improvement. However, national identity cannot simply be considered to equal economic development. Indeed, people's national identity belongs to an ideological scope, which is also affected by other factors. Especially for ethnic minorities' sports culture, cultural accumulation of ethnic minorities is relatively poor. If we do not value satisfaction and response to their cultural demands, various kinds of national problems will be caused easily. This requires that we should pay attention to caring for and responding to increasingly growing spiritual and cultural demands of people and realize people's high national identity via reasonable guidance about cultural consumption.
\end{abstract}

\section{Developmental outline about core thoughts of social governance theory}

It is in the 1980s that social governance theory rose for the first time. It is a kind of theory deriving from public management and its main opinion deems that public affairs should not be handled by the government only but be new-type management about social public affairs which have joint participation of the government, market and citizens and where they play a role jointly. Since force of participation integrates many kinds in this process, it is easier to realize maximization of public benefits and help with harmony and stability of social order. Social governance theory takes root in unity of opposites of interest relationship among the government, market and citizens. Over many years' development, it has played an important role in public management up to now.

Basic core thoughts of social governance theory can be summarized as the following aspects:

(1) Multi-subject theory about social governance. The theory thinks that the said governance is different from compulsive ruling. Social theory needs authority as well, but the authority does not come from the government only. With respect to relationship among the government, market and citizens, governance theory holds that the previous hierarchical administrative management will be replaced with more equal and more harmonious management system, and the government is not the only owner monopolizing all public service and public products but will be changed to the role that provides public service more fairly and ensures all kinds of system can be perfected and guaranteed. 
Then, the government can spend more time which used to be spent on many trivial matters, make full use of various management styles of sociology and carry out comprehensive coordination and implementation. Thus, it will be more helpful for the government to make long-term and scientific decisions and plans and promote efficient development of the society.

(2) Diversified social management tools or approaches. Under guidance of governance theory, social management implements technical remodeling and management process reengineering by more diversified social management tools and more scientific management methods and techniques in order to improve the government's work efficiency and transparency of government affair disclosure, promote coordination and unification of government reform and social public service via all kinds of new theories and new methods, bring more diversification to participants of public service and realize socialization of public service. Governance theory thinks that the government should consider interest demands of different stratums when it makes and issues social guidelines and various policies and ensure social benefits can benefit more audience by fairness and unification of social benefits, especially people holing a weak position in stratum because of classification of social stratum and pursuit of interest are different. This requires approaches by which rights are realized should be diversified from another perspective.

\section{Connotation of mechanism about response to cultural demands}

\section{Mechanism about information acquisition about cultural demands}

To realize rapid response to ethnic minorities' sports culture demands, the government should establish and perfect all kinds of information feedback channels first and thus can know ethnic minorities' sports culture demands accurately and timely. Scientific and accurate information feedback related to cultural demands is a key by which the government learns ethnic minorities' sports culture demands, and premise on which the government makes response with pertinence. Although there are many ways to get ethnic minorities' sports culture demands, such ways can be summarized as the following aspects: (1) various demands given by the public directly, for instance, building stadiums, reading rooms, libraries and cultural palaces to satisfy ethnic people's increasingly growing demands for sports learning; (2) government sectors collect and acquire situations about satisfaction with ethnic minorities' sports culture demands by secondary data, including investigation and survey and research literatures, such as the situation about whether they can obtain various cultural information conveniently and their mastery about socialist culture etc.; (3) suggestions of experts, scholars, researchers and news media etc. It must be pointed out that we should not adopt one or two of such channels but collect and acquire all kinds of information about cultural demands via several channels compressively and openly so that we can get correct and timely response via related feedback mechanism and help with the public's cultural appeal and cultural consumption, although there are the foregoing main channels by which information about cultural demands can be obtained.

\section{Mechanism about response to cultural appeal}

The said mechanism about response to cultural appeal mainly means decision-making feedback system of culture can process various types of information about cultural demands, form all kinds of processing opinions and decisions rapidly and apply them to guide practice. The key to the mechanism about response to cultural appeal lies in high efficiency and accuracy of information processing. Besides, the mechanism should have some foreseeability. In another word, implementation if cultural policy should not only be based on ethnic minorities' sports culture demands currently but focus on potential cultural demands in future.

\section{Mechanism about cultural information conduction}

Scientific and effective mechanism about cultural information conduction can not only give feedback about various kinds of information related to cultural demands accurately for decision-makers to make judgment and decisions more accurately but also enhance information interaction between the public and decision-makers effectively. If the mechanism about cultural 
information conduction is reasonable enough, this kind of information interaction will not cause any obstacle. In addition, this type of network requires strong covering power. Since different social members stay in different social groups or stratum, media may be different. This puts forward quite high demands for communication efficiency of information in different media.

\section{Analysis about connotation of national identity}

National identity is a concept for all citizens in stratum, which means their psychic reaction to their countries and positions and images of their countries in their mind. This psychic reaction is not changeless. Considering emotional interaction generated in the process of national identity, citizens assign their activities and interests to their country purposefully or unwittingly. Thus, centripetal force maintaining national interest is formed, which drives individuals to support and advocate all policies, political system and ideology of the country.

\section{Construction strategies about the mechanism about response to ethnic minorities' sports culture demands based on social governance theory}

Good social governance cannot be separated from perfect information response mechanism. In other words, from a certain perspective, response even acts as a precondition and only accurate, rapid and scientific response can provide primary data for effective governance. This requires us should protect ethnic minorities' sports culture and etiquette and work hard to construct positive and effective mechanism about response to sports culture demands when we build the mechanism about response to sports culture demands for them. Only in this way can we integrate the country, ethnic cultural concept, political policy and advanced culture with ethnic minorities' social development, contribute to unification, unity and stability of all peoples and realize long-term peace and order of the country. However, being restricted by various factors, the government still has some dissatisfactory parts in its response to ethnic minorities' sports culture appeal. Additionally, it is required that the government should make more efforts and adopts several methods comprehensively to realize scientific perfection of the mechanism about response to ethnic minorities' sports culture demands and construct new-type mechanism about response to culture demands.

Firstly, subjects that sports culture governance of ethnic minorities requires being contained should be diversified. As mentioned above, although the process of governance cannot be separated from guidance of authoritative force, source of the force does not contain the government only. Under traditional governance modes about ethnic minorities' sports culture, the government provides the only force source. Obviously, it is not reasonable to rely on the government only to respond to ethnic minorities' sports culture. Indeed, this practice has limitations to a large extent. Under the social governance based on social governance theory, it is requested that authoritative force should derive from many aspects and the government, social organizations and citizens should be allowed to take part in fair interaction, give their voice for cultural demands and fight for their vital interests. Similarly, we know ethnic minorities' sports culture demands cannot be separated from joint participation and interaction of the government, social organizations and citizens and they drive development of ethnic minorities' sports culture undertakings constantly in this process.

Secondly, another obvious feature of sports culture governance mode is subjectification of objects. In traditional management modes about sports culture, relevant people of cultural benefits cannot decide realization of their own interest but passively accept the government's cultural policy management and all decisions. Obviously, this is not reasonable enough. Under social governance theory, it is required that relevant people of cultural benefits should change into dominant leaders from a position of passive acceptation and take part in processes of cultural policies, such as establishment, implementation and supervision etc. In doing so, we can drive the government's cultural policy to reflect people's demands and represent their wish more effectively and satisfy their sports culture benefits better.

Thirdly, we should advance cultural marketization and industrialization development actively. 
Cultural industry is another new-type industry which is different from traditional economic industry. After entering the 21st century, cultural industry becomes increasingly active. Because of its impacts on people's thoughts, it is even placed at a strategic height and becomes important support for soft power of the country. In traditional cultural management, culture has been present in front of the public by a role with public welfare and non-profitability and been supported and guaranteed by governmental finance and public sources to a larger extent for a long time. It is no doubt that this restricts cultural development and results in insufficient vitality and innovation largely. What's more, response to people's cultural demands becomes an empty talk. However, under social governance theory, culture is operated as an industry and it is advocated that more enterprises and people are driven to take part in supply of cultural products and service by force of marketization and profitability and the government focuses on developing some cultural service projects with strong public welfare. In this way, labor division and developmental level provided and created by culture are clearer. As a result, powerful system that drives culture service is formed and it will be more helpful for the country to satisfy increasingly growing cultural demands of people. This thought is appropriate for response to ethnic minorities' sports culture as well. It is essential to construct cultural service network that is multi-layered and even customized according to individuals' personality so as to satisfy ethnic minorities' sports culture demands effectively and improve the government's ability to respond constantly.

Fourthly, optimize the mechanism about cultural information conduction and construct more efficient transfer network. By virtue of cultural information network, cultural information can collect and give feedback about cultural appeal of people at all stratums and submit summaries to the government. At the same time, the government can also transfer various kinds of cultural information to the public by network and give response to the public's cultural appeal. Because traditional cultural management has many hierarchies of information conduction, few approaches, the public's difficulty in cultural appeal, large degree of distortion and even blocking, it is difficult for the public's cultural appeal to receive effective policy feedback. However, networking transferred by cultural information can enrich information transfer channels and methods, enhance information interaction between the government and the public more efficiently and accurately and ensures cultural demands can get timely and rapid response.

Fifthly, enlarge assessment on the government's responsibility for response. In traditional modes, cultural demands have stayed at an embarrassing weak position in assessment of governmental sections for a long period so that it is not essential or its size is changeable, which leads to situation that cultural response cannot be included in governmental actions effectively. In new-type governmental response mechanism, it is required that the government should assess citizens' cultural demands, be responsible and amenable and accept strict assessment. Only in this way can the public's cultural appeal be driven effectively to obtain the government's response.

\section{Conclusion}

Cultural governance is a dynamic and developing process, which needs continuous innovation and development. In the process in which the government responds to ethnic minorities' sports culture demands, the government need exert its functions sufficiently, mobilize all force comprehensively, form reasonable cultural promotion and work hard to satisfy ethnic minorities' sports culture demands. Thus, the government can improve their national identity more effectively and realize social harmonious development and long-term peace and order of the country finally.

\section{Reference}

[1] Wang Chufu. Response mechanism of pubic policy and pubic policy [J]. Journal of Jiangxi Administration Institute, 2009(2).

[2] James ·N. Rosena. Governance without government [M]. Nanchang: Jiangxi People's 
Publishing House, 2001(5).

[3] Xu Liude. Effect characteristic economy on sustainable development of minority culture [J]. Tangdu Journal, 2004(01). 